\title{
ESTRATÉGIAS DA ENFERMAGEM PARA INCLUSÃO DO HOMEM NO PROGRAMA DE PLANEJAMENTO FAMILIAR: UMA REVISÃO INTEGRATIVA
}

\section{REVISÃO INTEGRATIVA}

RIBEIRO, Ricardo Lennon Santana ${ }^{1}$, SOUSA, Haigle Reckziegel de ${ }^{2}$, MEDEIROS, Felype Hanns Alves de ${ }^{3}$, COELHO, Rafael Vilanova ${ }^{4}$, QUEIROZ, Patrícia dos Santos Silva ${ }^{5}$

RIBEIRO, Ricardo Lennon Santana. Et al. Estratégias da enfermagem para inclusão do homem no programa de planejamento familiar: uma revisão integrativa. Revista Científica Multidisciplinar Núcleo do Conhecimento. Ano 06, Ed. 09, Vol. 04, pp. 149-161. Setembro de 2021. ISSN: 2448-0959, Link de acesso: https://www.nucleodoconhecimento.com.br/saude/inclusao-do-homem, DOI: 10.32749/nucleodoconhecimento.com.br/saude/inclusao-do-homem

\section{RESUMO}

O planejamento familiar é um tema abordado na atenção básica de saúde e constitui um conjunto de ações que permitem a mulher, o homem ou o casal terem ou não seus filhos. Ainda que o planejamento reprodutivo ou familiar seja um espaço para homens e mulheres, é visível a ausência da participação masculina. Nesse sentido, qual a estratégia da enfermagem para a participação do homem no planejamento familiar? O presente trabalho teve como objetivo encontrar na literatura publicações que apresentassem estratégias dos profissionais de enfermagem para inclusão do homem no programa de planejamento familiar. Para alcançar esse objetivo foi realizada uma revisão integrativa em junho de 2021, utilizando as bases de dados

\footnotetext{
${ }^{1}$ Graduando em Enfermagem. ORCID: https://orcid.org/0000-0001-6648-5184

${ }^{2}$ Mestra, Coordenação de Curso e Docente. ORCID: http://orcid.org/0000-0002-5803-2289

${ }^{3}$ Especialista em Terapia Intensiva pela FABIC e Mestrando em Cirurgia Experimental pela UEPA. ORCID: http://orcid.org/0000-0001-5026-1995

${ }^{4}$ Graduando em Medicina. ORCID: https://orcid.org/0000-0002-3672-8410

${ }^{5}$ Orientadora. ORCID: http://orcid.org/0000-0002-9587-1786
}

RC: 97335

Disponível em: https://www.nucleodoconhecimento.com.br/saude/inclusao-dohomem 
Latino-Americana em Ciências da Saúde (LILACS) e Base de Dados de Enfermagem (BEDENF), sem restrição de idioma e publicados no período de 2011 a 2021. Após a busca na literatura científica, foram selecionados cinco estudos para análise quanto as estratégias dos profissionais na abordagem do tema com o público masculino. Todas as publicações encontradas apresentaram alguma sugestão relacionada à educação em saúde e/ou educação continuada ou capacitação profissional, algumas foram além pontuando como importante estratégia a captação ou acolhimento do homem que frequenta outros programas por diferentes patologias, além das ações em saúde direcionadas à família e a comunidade. Foi possível concluir que o profissional da saúde em especial a enfermagem deve atuar em estratégias de educação em saúde, mas dirigidas a realidade local, além de formação continuada para mudança de conceitos ultrapassados e fixados sobre o tema, visando incluir o homem no programa de planejamento familiar.

Descritores: Planejamento Familiar, Paternidade Responsável, Educação em Saúde, Enfermagem, Atenção Básica à Saúde.

\section{INTRODUÇÃO}

Embora não seja totalmente difundido o planejamento familiar possui lei específica no Brasil, que regula o $\S 7^{0}$ do art. 226 da Constituição da República Federativa do Brasil de 1988 (BRASIL, 1988). Este parágrafo estabelece que o planejamento familiar é fundado nos princípios da dignidade da pessoa humana e da paternidade responsável, e ao Estado compete propiciar os recursos educacionais e científicos para o exercício deste direito (BRASIL, 1988). Dessa forma, a referida lei, denominada Lei no 9.263, de 12 de janeiro de 1996, dispõe sobre o que trata o planejamento familiar.

O planejamento familiar é um conjunto de ações que permitem a mulher, o homem ou o casal terem ou não mais filhos. Ainda que o planejamento reprodutivo ou familiar seja um espaço para homens e mulheres, é visível que o maior público de

RC: 97335

Disponível em: https://www.nucleodoconhecimento.com.br/saude/inclusao-dohomem 
participação presente são as mulheres (MORAIS et al., 2014). Isso é devido, consequentemente, à uma construção histórica de gênero, social e cultural deque ainda pertence à mulher a decisão da contracepção (CASARIN e SIQUEIRA, 2014). Consequentemente, recai muitas vezes sobre os ombros delas a responsabilidade exclusiva por gestações não planejadas (CHIESA; SANCHES e SIMÃO-SILVA, 2019).

Há também de se considerar o enfoque demasiadamente restrito às mulheres, desde a década de 1980, em programas de planejamento familiar no âmbito dos serviços de saúde, realizados em ambientes não convidativos para o público masculino e que favorecem a mentalidade de que o assunto é exclusivamente delas (CHIESA; SANCHES e SIMÃO-SILVA, 2019; MORAIS et al., 2014; SILVA et al., 2018).

Considerando que a concepção é resultado natural e sexual entre um homem e uma mulher, é imprescindível a implementação de ações educativas, que contribuam com a construção da igualdade de gênero na escolha do método contraceptivo do casal, por exemplo (DIAS et al., 2017).

Nesse sentido a assistência no planejamento familiar necessita incluir os homens, fornecendo subsídios para sua participação ativa e reconhecimento do casal e da família como unidade de cuidado (PADILHA e SANCHES, 2020).

Com isso, o presente trabalho tem como questão norteadora: Qual a estratégia da enfermagem para a participação do homem no planejamento familiar? Tendo como objetivo geral analisar publicações que apresentassem estratégias dos profissionais de enfermagem para inclusão do homem no programa de planejamento familiar.

\section{METODOLOGIA}

Trata-se de um estudo de revisão integrativa realizado em junho de 2021, o qual é caracterizado pela capacidade de agrupamento e síntese das evidências científicas

RC: 97335

Disponível em: https://www.nucleodoconhecimento.com.br/saude/inclusao-dohomem 
relevantes sobre um demarcado tema ou questão norteadora, contribuindo para o aprofundamento do conhecimento e sua melhor compreensão por fornecer um retrato da literatura naquele momento.

Para a elaboração da revisão integrativa, foram realizadas algumas etapas, sendo, a identificação da questão do estudo, critérios de busca nas bases de dados, identificação das informações que respondem ao tema planejamento familiar e por fim inclusão dos estudos que apresentam alguma intervenção da enfermagem para participação do homem no planejamento familiar.

Primeiramente, definiu-se a questão que conduziu ao estudo, que consistiu em: Qual a estratégia da enfermagem para a participação do homem no planejamento familiar?

Foram usados como critérios de inclusão os artigos que contivessem em seus resumos o seguinte Descritor em Ciências da saúde (DeCS): Planejamento familiar e homem, artigos com resumos e textos completos disponíveis para análise publicados no período de 2011 a 2021, nos idiomas português, inglês e espanhol. Como critério de exclusão, capítulos de livros.

Realizaram-se buscas nas bases de dados Literatura Latino-Americana e do Caribe em Ciências da Saúde (LILACS) e na Base de Dados de Enfermagem (BDENF).

A partir da busca foram identificados 355 estudos na LILACS e 175 estudos na BDENF, após aplicar a inclusão, apenas textos completos e planejamento familiar presente no título, foram obtidos 54 artigos. Em seguida, foi feita a seleção dos que apresentavam algum indício sobre a participação masculina no planejamento familiar, obtendo, por fim, seis artigos que foram avaliados para responder à questão de estudo.

Os objetivos, resultados, e conclusões desses artigos foram distribuídos em uma planilha de coleta de dados, para facilitar a identificação das intervenções da enfermagem.

RC: 97335

Disponível em: https://www.nucleodoconhecimento.com.br/saude/inclusao-dohomem 
A síntese dos estudos foi desenvolvida de forma descritiva em relação aos objetivos, resultados e conclusões.

\section{RESULTADOS}

A busca sobre as estratégias usadas pelos profissionais da saúde em especial da enfermagem na literatura científica resultou na seleção de seis estudos, conforme apresentado na Figura 1, a seguir.

Figura 1 - Fluxograma da seleção dos estudos recuperados nas bases de dados, adaptado do Preferred Reporting Items for Systematic Review and Meta-Analyses (PRISMA), sobre as estratégias da enfermagem na inclusão do homem no planejamento familiar.

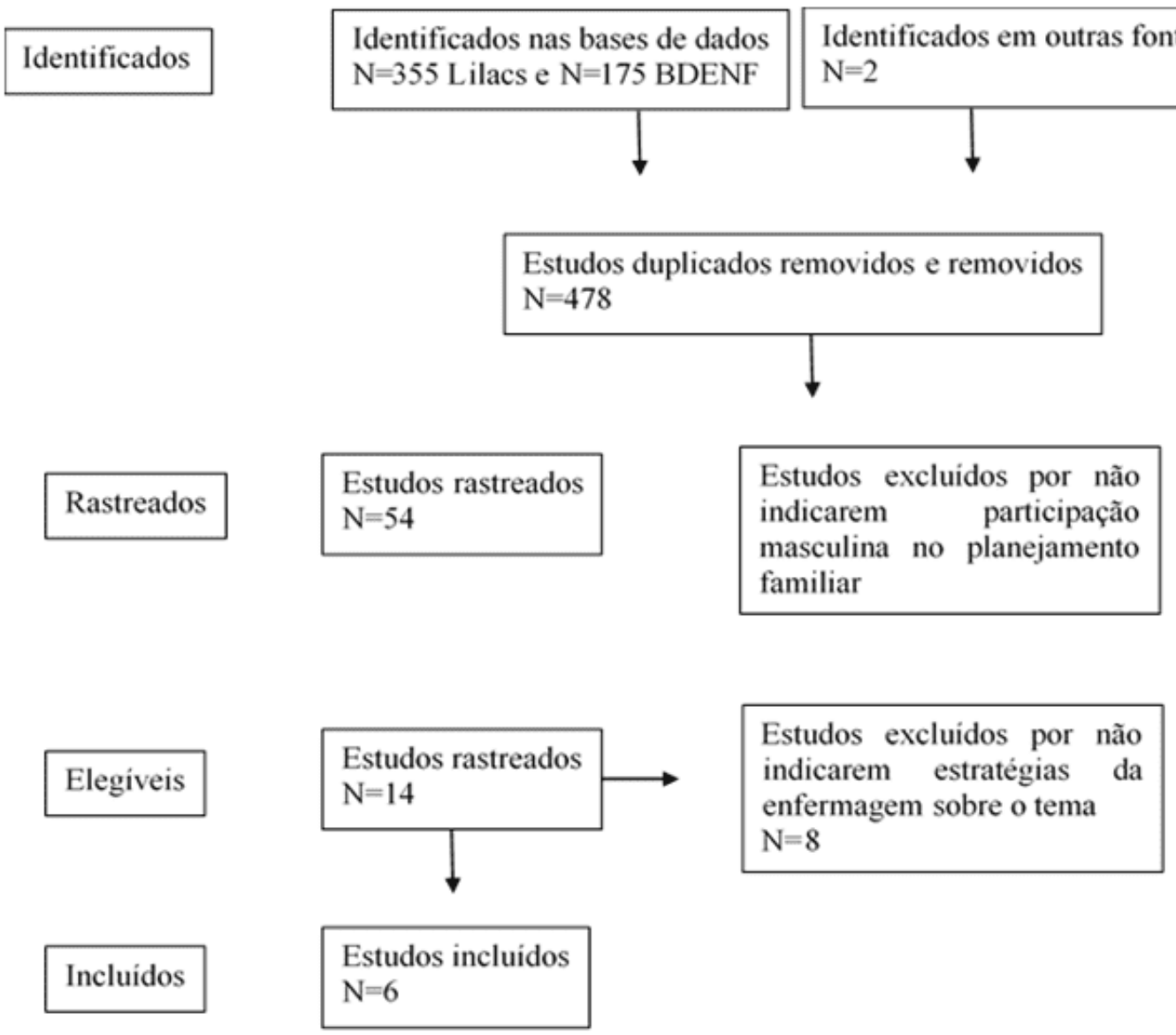

Fonte: arquivo próprio.

RC: 97335

Disponível em: https://www.nucleodoconhecimento.com.br/saude/inclusao-dohomem 
Todas as publicações encontradas a partir dos critérios de busca foram investigadas quanto a participação masculina no programa de planejamento familiar e após foram selecionadas as publicações que apresentaram alguma estratégia dos profissionais da saúde e/ou enfermagem sobre a inclusão do homem no programa. Os principais achados dos trabalhos encontrados são apresentados na Figura 2, a seguir.

Figura 2 - Caracterização dos estudos incluídos na revisão integrativa quanto ao objetivo, resultados principais e conclusões sobre as estratégias de intervenção da enfermagem.

\begin{tabular}{|c|c|c|c|c|}
\hline Código & Identificação & Objetivo & $\begin{array}{l}\text { Resultados } \\
\text { principais }\end{array}$ & Conclusões \\
\hline E1 & $\begin{array}{l}\text { Sauthier } \\
\text { (2011) }\end{array}$ & 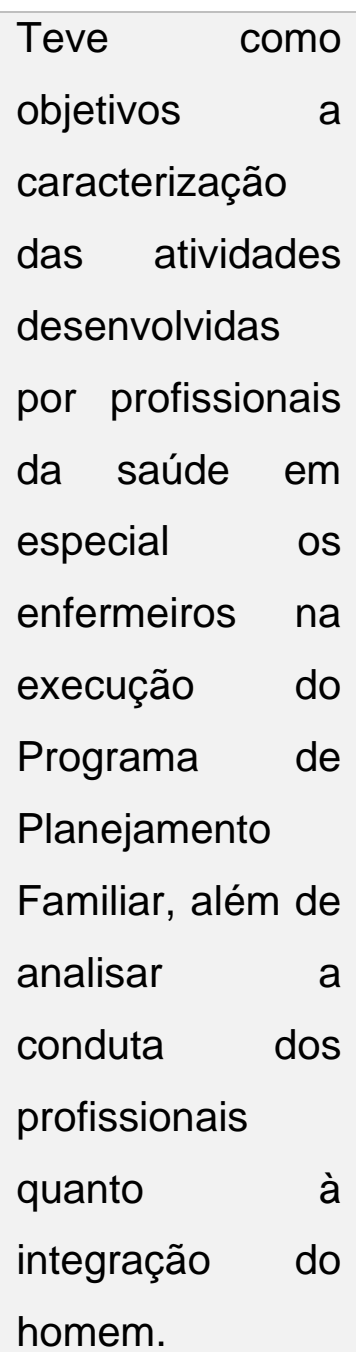 & $\begin{array}{l}\text { Constatou que os } \\
\text { papéis de gênero na } \\
\text { sociedade são } \\
\text { conceitos, que } \\
\text { dificultam a inclusão } \\
\text { do homem no } \\
\text { programa e estão } \\
\text { cristalizados entre } \\
\text { os profissionais da } \\
\text { saúde. O autor } \\
\text { ressalta que deve } \\
\text { ocorrer, inicialmente, } \\
\text { uma mudança de } \\
\text { paradigmas entre os } \\
\text { profissionais, além } \\
\text { de ações educativas } \\
\text { em outras esferas }\end{array}$ & $\begin{array}{l}\text { A política de } \\
\text { trazer o homem } \\
\text { para o centro das } \\
\text { discussões } \\
\text { existe na } \\
\text { proposta do } \\
\text { programa, mas, } \\
\text { na prática, é } \\
\text { falha. } \\
\text { Atualmente, o } \\
\text { programa do } \\
\text { planejamento } \\
\text { familiar encontra- } \\
\text { se implementado } \\
\text { como ação } \\
\text { educativa e } \\
\text { clínica nas } \\
\text { instituições } \\
\text { estudadas, }\end{array}$ \\
\hline
\end{tabular}




\begin{tabular}{|c|c|c|c|c|}
\hline & & & & $\begin{array}{l}\text { sendo a ação } \\
\text { educativa } \\
\text { realizadas por } \\
\text { enfermeiras } \\
\text { assistentes } \\
\text { sociais. }\end{array}$ \\
\hline E2 & Dias (2017) & 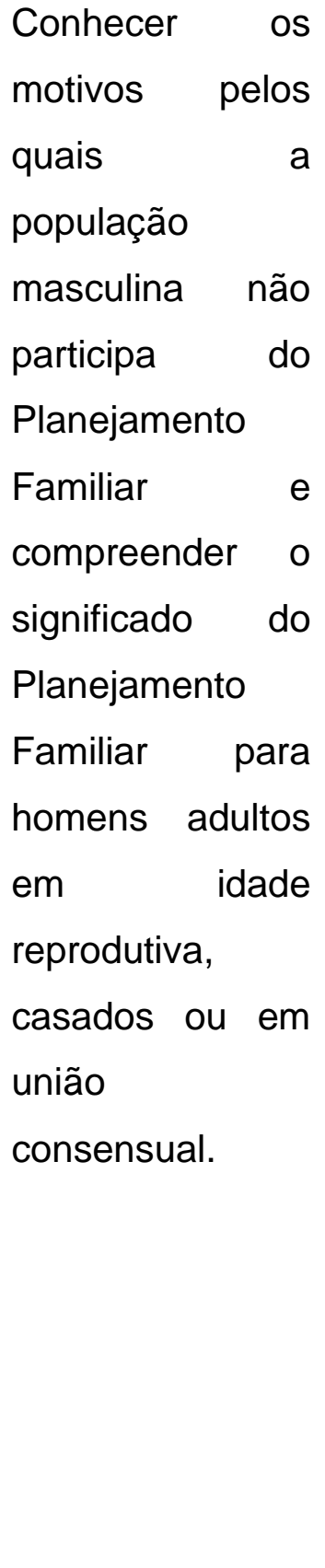 & 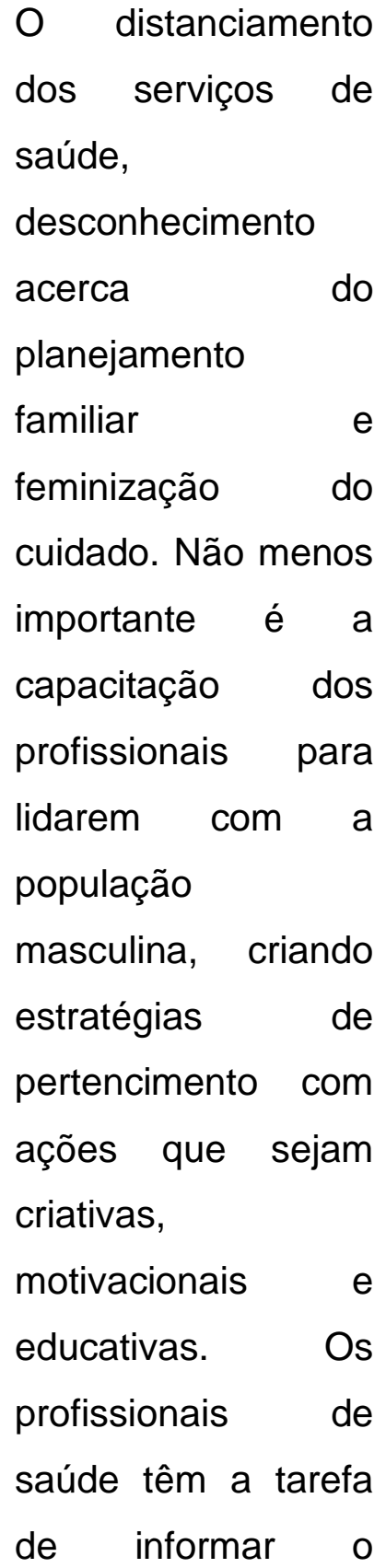 & $\begin{array}{l}\text { Constataram que } \\
\text { é necessário } \\
\text { ampliar o diálogo } \\
\text { e reorganizar as } \\
\text { estratégias de } \\
\text { planejamento e } \\
\text { gestão para } \\
\text { encorajar } \\
\text { conferir a devida } \\
\text { importância que } \\
\text { os homens } \\
\text { possuem nesse } \\
\text { cenário de } \\
\text { diálogo } \\
\text { decisões sobre a } \\
\text { própria família. }\end{array}$ \\
\hline
\end{tabular}

RC: 97335

Disponível em: https://www.nucleodoconhecimento.com.br/saude/inclusao-do- 


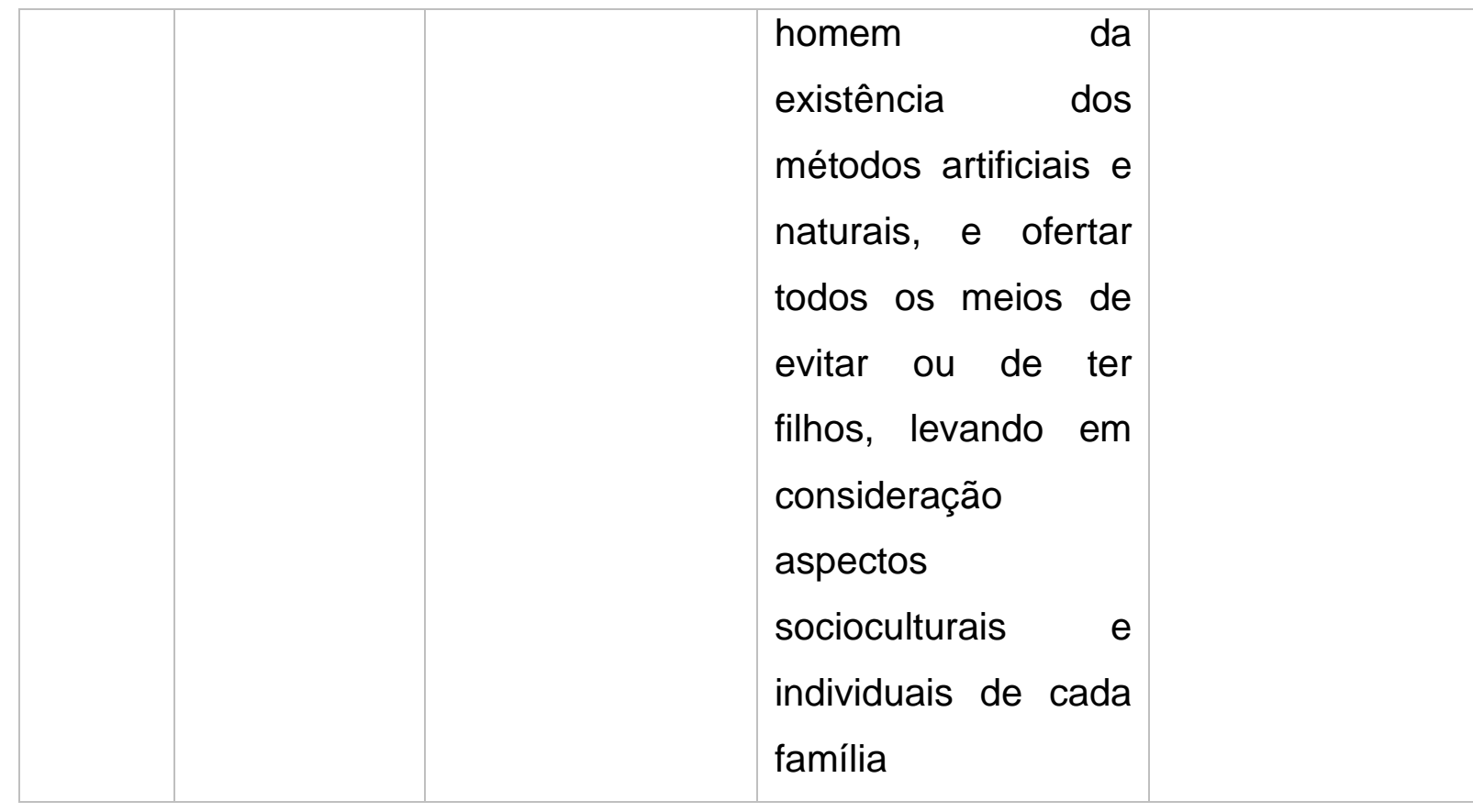

\section{Resultados principais Conclusões}

Identificou quatro Concluíram a

artigos sendo que três necessidade de deles demonstraram ações educativas, Com o objetivo que as orientações tanto aos encontrar na referentes à temática, profissionais de literatura tanto individuais como saúde como aos orientações em grupo, são usuários dos sobre papel do realizadas por serviços, que

E3

\begin{tabular}{|c|c|c|}
\hline 19) & $\begin{array}{l}\text { profissional } \\
\text { saúde } \\
\text { planejamento } \\
\text { familiar } \\
\text { identificou } \\
\text { quatro artigos }\end{array}$ & 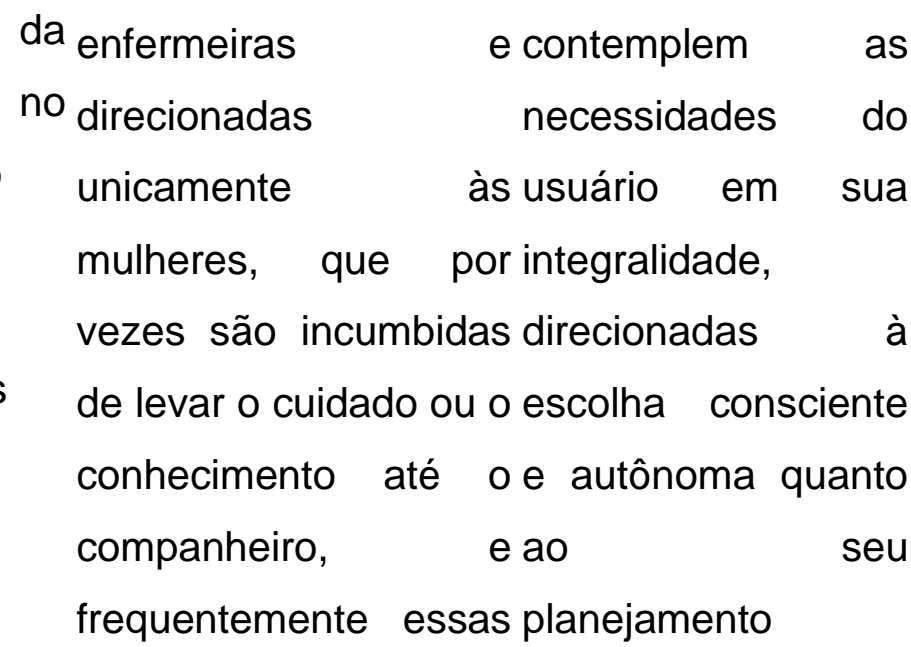 \\
\hline
\end{tabular}

RC: 97335

Disponível em: https://www.nucleodoconhecimento.com.br/saude/inclusao-dohomem 


$$
\text { orientações não reprodutivo. }
$$$$
\text { alcançam os homens. }
$$$$
\text { Além disso os autores }
$$$$
\text { identificaram uma }
$$$$
\text { carência por parte dos }
$$$$
\text { profissionais da }
$$$$
\text { atenção básica, de }
$$$$
\text { tentativas e estratégias }
$$$$
\text { para incluir os homens }
$$$$
\text { nesses cuidados, }
$$$$
\text { evidenciando pouco }
$$$$
\text { interesse por parte }
$$$$
\text { desses profissionais }
$$$$
\text { em mudar essa }
$$$$
\text { realidade. Como }
$$$$
\text { estratégias os autores }
$$$$
\text { citam a educação }
$$$$
\text { continuada dos }
$$$$
\text { profissionais da saúde }
$$$$
\text { e inclusão do homem }
$$$$
\text { que frequenta a }
$$$$
\text { atenção básica em }
$$$$
\text { programas como de }
$$$$
\text { diabetes e hipertensão, }
$$$$
\text { por exemplo }
$$

Código Identificação Objetivo Teve como Verificaram que os Os profissionais

E4 Reis (2013) objetivo identificar profissionais de saúde devem ser o desejo de ter nem sempre capacitados e 
filhos e as apresentavam postura sensibilizados para estratégias acolhedora sobre opromover adotadas para desejo ou não de atendimento e planejamento concepção e segundo orientação aos familiar e os autores o casais soro utilização de planejamento familiar é discordantes, métodos discutido de maneira abordando contraceptivos. insuficiente entre planejamento casais sorofamiliar e suas discordantes. Para eles decisões os profissionais reprodutivas.

deveriam ser
capacitados
sensibilizados para
promover atendimento
e orientações aos
casais, abordando
planejamento familiar e
suas decisões
reprodutivas

E5

Silva (2018)

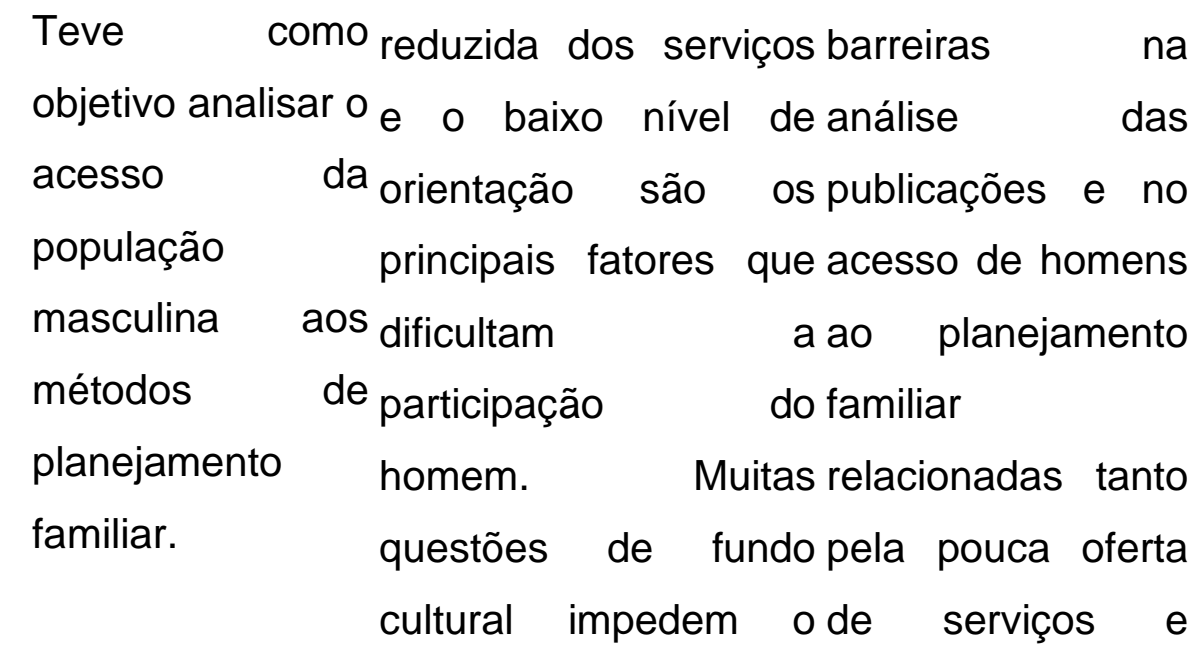

RC: 97335

Disponível em: https://www.nucleodoconhecimento.com.br/saude/inclusao-dohomem 


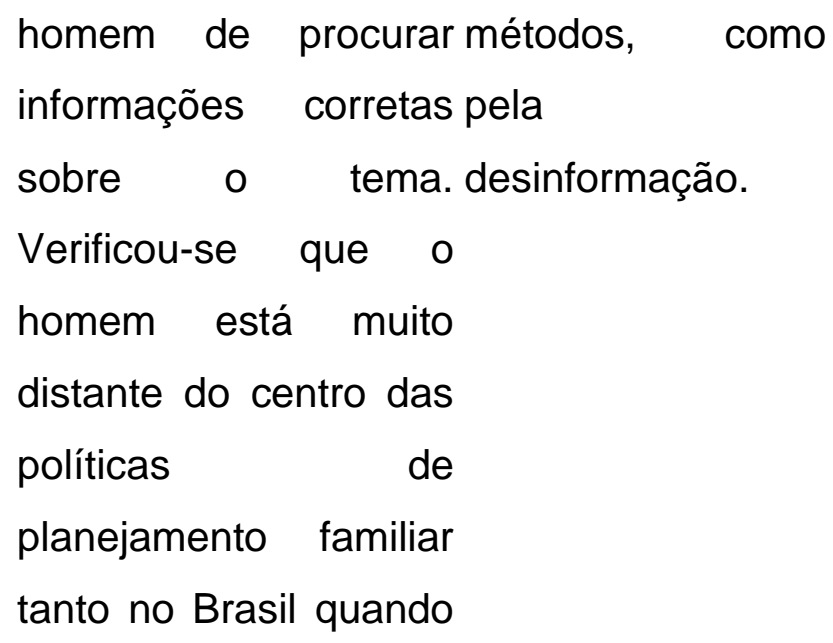


equipe.

Fonte: arquivo próprio.

\section{DISCUSSÃO}

Através dos artigos analisados, bem como outros trabalhos publicados, foi possível identificar a participação reduzida da população masculina no planejamento familiar e vários fatores que contribuem para essa realidade (ALVES et al., 2019; MOZZAQUATRO e ARPINI, 2017; SAUTHIER e GOMES, 2011; SILVA et al., 2013). Como o objetivo do presente trabalho foi identificar as contribuições da enfermagem para o enfrentamento dessa realidade podemos citar a educação em saúde e educação continuada como ferramenta para mudança de paradigmas.

Todos os trabalhos apresentam alguma sugestão relacionada a educação em saúde (SAUTHIER, 2011; DIAS, 2017; ALVES, 2019; REIS, 2013; SILVA, 2018), outros mencionam a importância da educação continuada ou capacitação profissional (DIAS, 2017; ALVES, 2019; SILVA, 2018). Algumas especificidades foram encontradas nos estudos de Alves (2019) e Reis (2013). Onde Alves (2019), pontua com uma importante estratégia a captação ou acolhimento do homem que frequenta outros programas por patologias específicas como hipertensão e diabetes, por exemplo, Reis (2013) defende que as ações em saúde não devem ser restritas ao homem ou a mulher, mas direcionadas a família para uma melhor adesão.

As ações necessárias se aplicam também à equipe de enfermagem e demais profissionais da saúde que por vezes abordam o tema com os mesmos preconceitos e paradigmas apresentados pelos usuários. Nesse processo de capacitação profissional, destacaram-se os materiais educativos impressos como ferramentas que auxiliam na educação em saúde, tanto na visão do profissional como do usuário (ALVES et al., 2019) 
Os enfermeiros envolvidos no planejamento familiar devem considerar as particularidades regionais como abordado por Silva (2018), uma vez que em regiões economicamente desfavorecidas a adesão do homem é ainda menor quando comparadas a regiões mais desenvolvidas (PADILHA e SANCHES, 2020). Aspectos culturais bem como o desenvolvimento econômico estão implicados em uma maior ou menor participação do homem (SILVA et al., 2018).

Além de ações educativas individuadas e voltadas para a realidade local outro fator importante é o ambiente físico das unidades de saúde que priorizam mulheres e crianças ocasionando, assim, sentimentos de vergonha, preconceito e medo de ostentar fragilidade que atuam afastando o público masculino dos serviços de saúde, influenciando de maneira negativa a busca por ações de controle da fecundidade. A feminilização do cuidado nas unidades básicas de saúde foi abordada por Dias (2017) onde os homens sentem até certo constrangimento em frequentar os programas (SAUTHIER e GOMES, 2011).

Os profissionais de saúde têm a tarefa fundamental de incentivar o público masculino a uma participação ativa no planejamento familiar, convidando ambos mulheres e homens sem distinção para reuniões sobre o tema, reforçando a necessidade do acesso dos homens ao atendimento público de saúde e evitar a falha dos profissionais envolvidos, ao inserir somente as mulheres nas discussões referentes ao planejamento (CASARIN e SIQUEIRA, 2014).

A distinção entre assuntos de homem e assuntos de mulher, é uma atitude que cristaliza ainda mais os preconceitos. Nesse sentido os profissionais devem atuar promovendo a equidade de gênero e estimulando uma nova forma de participação masculina e o poder público deve fornecer espaço e profissionais capacitados para o programa (SAUTHIER e GOMES, 2011).

RC: 97335

Disponível em: https://www.nucleodoconhecimento.com.br/saude/inclusao-dohomem 


\section{CONCLUSÃO}

Em relação ao programa de planejamento familiar fica evidente a pouca participação masculina que pode ser explicada por diferentes fatores socioculturais e ou socioeconômicos. Ao responder sobre quais estratégias poderiam ser utilizados pelos profissionais da saúde, em especial a enfermagem, constatou-se que os mesmos devem atuar em estratégias de educação em saúde, porém dirigidas a realidade local, além de formação continuada para mudança de conceitos ultrapassados e fixados em esses profissionais sobre o tema planejamento familiar, visando incluir o homem no programa de planejamento familiar.

\section{REFERÊNCIAS}

ALVES, A. M. et al. Planejamento reprodutivo nas orientações em saúde: revisão integrativa. Revista Família, Ciclos de Vida e Saúde no Contexto Social, v. 7, n. 3, p. 366-377, 1 jul. 2019.

BRASIL. Constituicao-Compilado. Disponível em: <http://www.planalto.gov.br/ccivil_03/constituicao/constituicaocompilado.htm>. Acesso em: 10 jun. 2021.

CASARIN, S. T.; SIQUEIRA, H. C. H. DE. Family planning and men's health from nurses' perspective. Escola Anna Nery - Revista de Enfermagem, v. 18, n. 4, 2014.

CHIESA, D. D. P.; SANCHES, M. A.; SIMÃO-SILVA, D. P. PLANEJAMENTO FAMILIAR COMO ASSUNTO DE MULHER!? PERFIL DE GÊNERO NA PRODUÇÃO CIENTÍFICA NO BRASIL. Revista Interdisciplinar de Estudos em Saúde, v. 8, n. 1, p. 221-235, 1 jul. 2019.

DIAS, M. G. et al. A participação masculina no planejamento familiar. HU rev, p. 349-354, 2017.

RC: 97335

Disponível em: https://www.nucleodoconhecimento.com.br/saude/inclusao-dohomem 
MORAIS, A. C. B. DE et al. Participação masculina no planejamento familiar: o que pensam as mulheres? Cogitare enferm, p. 656-666, 2014.

MOZZAQUATRO, C. DE O.; ARPINI, D. M. Planejamento Familiar e Papéis Parentais: o Tradicional, a Mudança e os Novos Desafios. Psicologia: Ciência e Profissão, v. 37, n. 4, p. 923-938, dez. 2017.

PADILHA, T.; SANCHES, M. A. Participação masculina no planejamento familiar: revisão integrativa da literatura. Interface - Comunicação, Saúde, Educação, v. 24, 2020.

SALUD, S. DE. Intervenciones de enfermería para la promoción de la planificación familiar en hombres y mujeres. p. 41-41, 2015.

SAUTHIER, M.; GOMES, M. DA L. B. Gênero e planejamento familiar: uma abordagem ética sobre o compromisso profissional para a integração do homem. Revista Brasileira de Enfermagem, v. 64, n. 3, p. 457-464, jun. 2011.

SILVA, G. S. DA et al. Partner's participation in family planning from a feminine perspective: a descriptive study. Online braz. j. nurs. (Online), 2013.

SILVA, W. G. DA et al. O planejamento familiar para homens. Revista de Enfermagem UFPE on line, v. 12, n. 11, p. 3098, 6 nov. 2018.

Enviado: Agosto, 2021.

Aprovado: Setembro, 2021. 